\title{
Clinical outcome and analysis of procedural failure during uterine artery chemoembolisation as a treatment of caesarean scar pregnancy
}

\author{
Krzysztof Pyra ${ }^{1}$, Maciej Szmygin ${ }^{1}$, Viktor Bérczi ${ }^{2}$, Maria Tsitskari $^{3}$, Michał Sojka ${ }^{1}$, Grzegorz Pietras ${ }^{4}$, \\ Sławomir Woźniak ${ }^{5}$ \\ ${ }^{1}$ Department of Interventional Radiology and Neuroradiology, Medical University of Lublin, Lublin, Poland \\ 2Department of Radiology, Medical Imaging Clinic, Semmelweis University Budapest, Budapest, Hungary \\ ${ }^{3}$ Vascular and Interventional Radiology, Apollonio Hospital, Nicosia, Cyprus \\ ${ }^{4}$ Department of Gynaecology and Perinatology, Medical University of Lublin, Lublin, Poland \\ ${ }^{5}$ Department of Gynaecology, Medical University of Lublin, Lublin, Poland
}

Videosurgery Miniinv

DOI: https://doi.org/10.5114/wiitm.2020.100713

\begin{abstract}
Introduction: Caesarean scar pregnancy (CSP) is a relatively rare yet life-threatening condition in which the embryo is implanted in the scar after caesarean section. Recent studies have reported that uterine artery chemoembolisation (UAC) can be safe and effective method in treating CSP.

Aim: To present the clinical outcome of UAC with a mixture of methotrexate and gelatine sponge for the treatment of CSP and analysis of procedural failure.

Material and methods: Forty-one patients diagnosed with CSP were treated with selective endovascular chemoembolisation of uterine arteries. Short- and long-term results, reasons for procedural failure, and clinical outcome were analysed.

Results: Primary procedure failed in 7 out of 41 (17\%) cases. In 4 cases additional blood supply to the CSP was disclosed; 3 out of 4 from an ovarian artery and one from a superior vesical artery. In other 3 patients, reperfusion of uterine arteries was observed. All these 7 patients underwent successful secondary embolisation. The majority of the followed-up patients reported regular menses after the intervention. Four women suffered from amenorrhoea and 2 from hypomenorrhoea that continued after 90 days. Twelve patients expressed the desire for subsequent pregnancy. From this group, 5 conceived within a year of the procedure. The rest did not achieve a pregnancy.

Conclusions: UAC proved to be a safe and effective method and should be considered as an option for CSP treatment, especially for women hoping to preserve their fertility. However, the presence of collateral blood supply should always be considered.
\end{abstract}

Key words: uterine artery embolisation, Caesarean scar pregnancy, endovascular, chemoembolisation.

\section{Introduction}

Caesarean scar pregnancy (CSP) is a moderately rare type of ectopic pregnancy, which involves a serious risk to life because the embryo is implanted in the scar left in the uterus following a Caesarean section. As a site of accumulation of fibrous tissue, the scar is considered a locus minoris resistentiae (a weakness) in the uterine wall, which predisposes

\section{Address for correspondence}

Dr. Maciej Szmygin, Department of Interventional Radiology and Neuroradiology, Medical University of Lublin, Lublin, Poland,

e-mail: mszmygin@gmail.com 
the patient to uterine rupture that may lead to massive haemorrhage, vaginal bleeding, shock, or other serious medical complications.

The first case of CSP was reported in 1978 by Larsen and Solomon [1], and since that time there has been a rising trend in the number of cases, as more and more babies have been delivered by Caesarean section. The growing incidence of CSP, which is now 1 in 800 to 1 in 2216 [2], has increased the awareness of the issue, and the resulting medical complications prompt experts to profile and establish standardised treatment guidelines for this condition. According to the Royal College of Obstetricians and Gynaecologists (RCOG), pregnancies located in the Caesarean scar are 'associated with severe maternal morbidity and mortality' [3]. Because the majority of patients undergoing CSP are young and have the strength to preserve fertility, several management approaches have been suggested. They comprise both surgical and non-surgical methods and depend on a number of crucial factors, such as gestational age, haemodynamic stability, or depth of the trophoblast invasion.

Recent studies in the field have shown that uterine artery chemoembolisation (UAC) may be a safe and effective method of treating CSP [4-6]. However, the failure rate of primary embolisation is as high as $20 \%$ [5], due to the anatomical and periprocedural risks.

\section{Aim}

The aim of this study was to investigate the effectiveness and safety of UAC and to analyse failed procedures and pregnancy delivery outcomes.

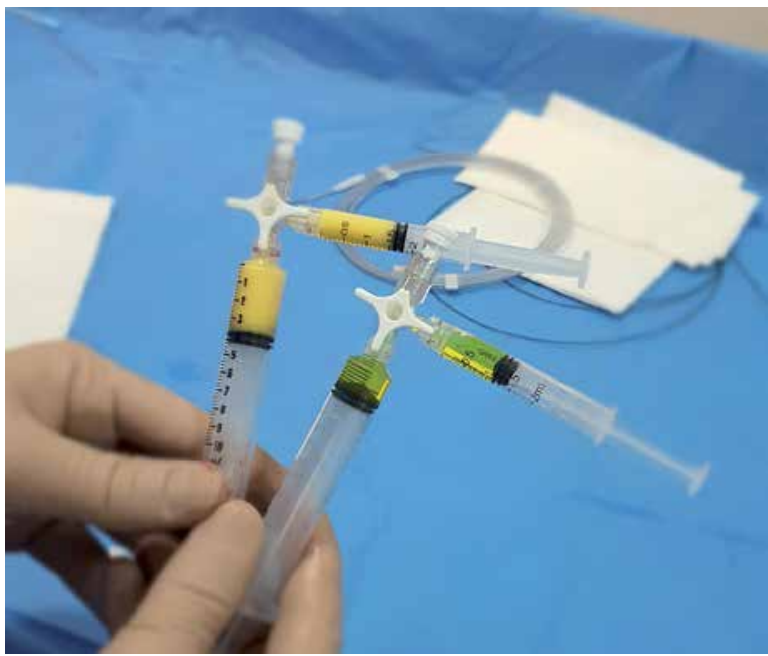

Photo 1. Materials used for embolisation - gelatine sponge (yellow) and methotrexate (green)

\section{Material and methods}

Clinical records of 41 CSP patients admitted to the Department of Interventional Radiology and Neuroradiology in the period from January 2013 to April 2019 were analysed. All cases of CSP and absence of intrauterine gestation were confirmed by TVUS examination. Also, magnetic resonance imaging (MRI) was carried out when the diagnosis was inconclusive. All procedures were performed in compliance with the ethical standards and were approved by the Local Ethics Committee.

\section{Uterine artery chemoembolisation}

Prior to the procedure, informed consent was obtained from all patients. Vascular access was obtained via the femoral artery, and initial angiography was executed using an RUC catheter at the level of internal iliac arteries in order to depict the anatomy and the origin of uterine arteries. Subsequently, superselective catheterisation of the uterine arteries was performed using a coaxial system microcatheter. A $50 \mathrm{mg}$ dose of methotrexate (MTX), $25 \mathrm{mg}$ in each uterine artery, was administered through the microcatheter. Initially, half the dose of MTX, in liquid form, was slowly injected (for $60 \mathrm{~s}$ ), and then the other half dose mixed with gelatine sponge powder (half the nominal volume of a $10 \mathrm{ml}$ syringe) and $5 \mathrm{ml}$ of a contrast agent was administered. The density of the suspension was low enough for it to be injected through the microcatheter (Photo 1). We used the microcatheter for precise and controlled administration of the gelatine sponge gel. We also wanted to preserve in this way the patency of the main catheter used in further angiographies.

Embolisation was continued until complete cessation of blood flow to the gestational sac was achieved. Control angiography performed directly after the procedure confirmed obliteration of vascular supply to the gestational sac and near-complete stasis of blood flow in both uterine arteries. During the procedure, additional IV analgesic treatment with Ketoprofen (100 mg), paracetamol (1000 mg), and morphine (up to $15 \mathrm{mg}: 3 \mathrm{mg}$ every $15 \mathrm{~min}$ ) was given to the patients if needed $(10 / 41-24.4 \%)$. Moreover, the patients received pain treatment for $24 \mathrm{~h}$ following the embolisation procedure.

After successful embolisation, the patients were treated with suction and curettage within the first $24 \mathrm{~h}$. 


\section{Results}

The clinical characteristics of the patients are presented in Table I. The mean age of the patients was $34-35$ years (range: $27-48$ years). The majority $(23 / 41 ; 56 \%)$ of the patients had a documented history of two or more Caesarean sections before the CSP. The mean serum $\beta$-hCG level was $20018.5 \mathrm{mlU} / \mathrm{ml}$, which corresponded to the mean gestation age of 7 weeks at the time of diagnosis. Foetal heart rate (FHR) was present in 29 (71\%) patients in the initial TVUS examination.

Primary chemoembolisation was successful in the case of 34 patients (i.e. 83\%). Procedural failure was defined as persistent vascularisation and persistent FHR determined by ultrasound within $24 \mathrm{~h}$ of the treatment. In order to manage these complications, the patients underwent repeated angiography and embolisation. In total, 7 (17\%) patients required
Table I. Clinical features of the patients treated with UAC

\begin{tabular}{|lc|}
\hline Variable & Results \\
\hline Mean age (range) [years] & $34.5(27-48)$ \\
\hline Caesarean sections, mean (range) & $1.8(1-3)$ \\
\hline Serum $\beta$-hCG level (range) $[\mathrm{mlU} / \mathrm{ml}]$ & $20018.5(76-78720)$ \\
\hline
\end{tabular}

the additional treatment. In 4 cases, additional blood supply to the CSP was revealed. In 3 cases, blood was supplied from the ovarian artery (Photo 2) and in 1 case from the superior vesical artery (Photo 3 ). In the 3 remaining patients, recanalisation of uterine arteries was observed.

All 7 patients successfully underwent the repeat embolisation, which was performed within $24 \mathrm{~h}$ of TVUS using the (same) technique described in the Methods section, followed by suction and curettage.
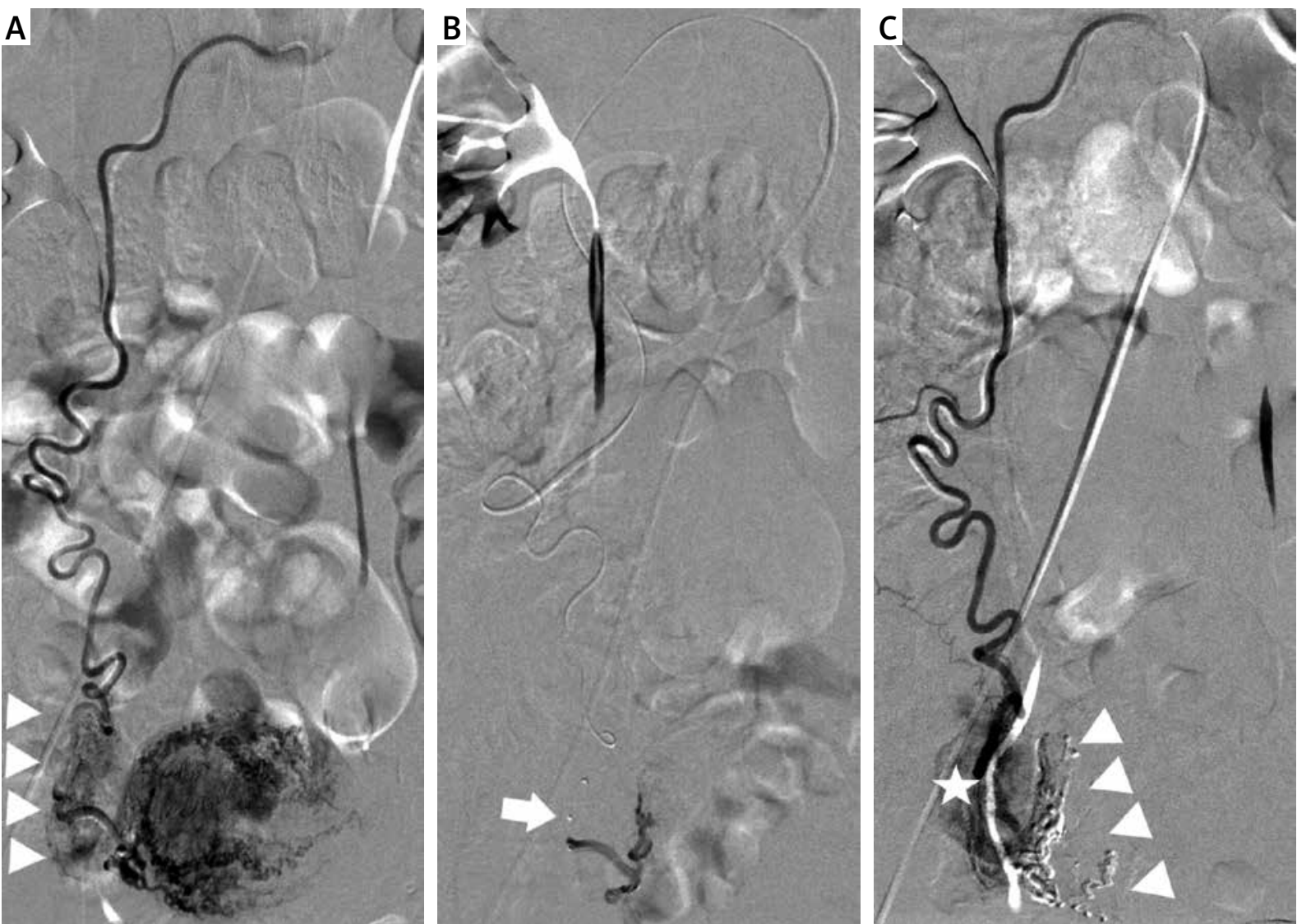

Photo 2. Additional blood supply to CSP from an ovarian artery. A - Selective angiography of the right ovarian artery from the main catheter. Visible blood supply to the right ovary (triangles). B - Super-selective angiography of blood supply to CSP from the microcatheter - branches supplying the right ovary are safely passed (arrow - tip of the microcatheter). C - Control angiography disclosing successful embolisation and preservation of blood supply to the right ovary (star). Visible glue cast (triangles) 


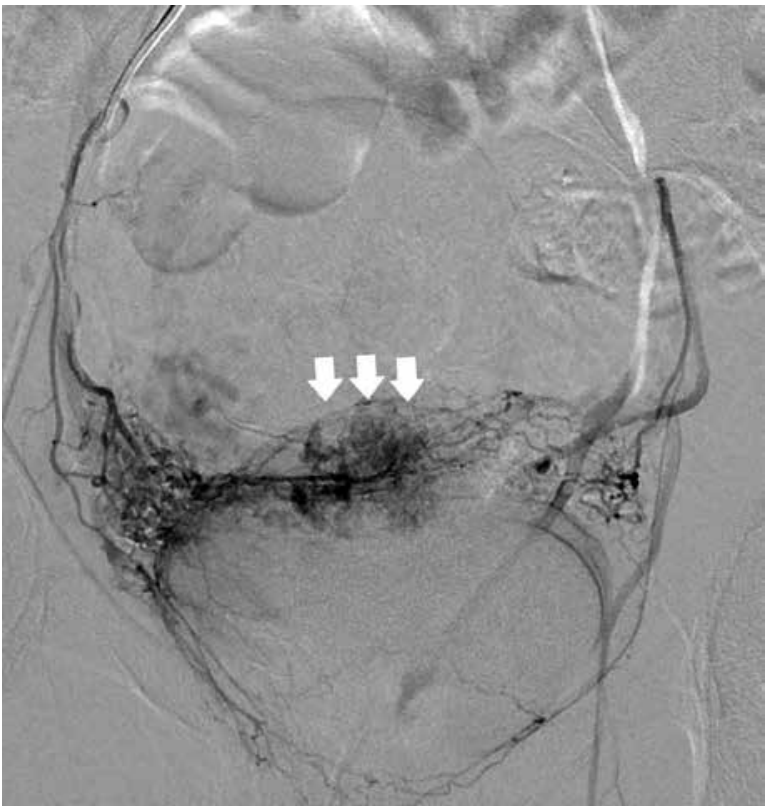

Photo 3. Additional blood supply to CSP from a superior vesical artery (arrows)

On average, the patients spent up to 6 days in hospital (range: 2-15 days), and no significant periprocedural complications were reported with in that time. The long-term follow-up ranged from 7 to 79 months, with a mean follow-up time of 27 months. Thirty-six women were evaluated, and 5 were lost to follow-up (could not be contacted). During that period, no major or clinically significant complications were noted.

Thirty out of the 36 patients (i.e. 83\%) reported a return to regular menses after the intervention. The mean time to return to menses was 41 days (range: 28-90 days). Four women suffered from permanent amenorrhoea, and 2 suffered from hypomenorrhoea at day 90 of the follow-up. The mean age of these patients was 37 years (amenorrhoea) and 36 years (hypomenorrhoea).

Twelve patients expressed a desire for future pregnancy. Of this group, 5 women conceived within 1 year of the procedure. Four of them underwent Caesarean section, and 1 had an early miscarriage. The remaining patients did not become pregnant during the follow-up.

\section{Discussion}

CSP is a special type of ectopic pregnancy in which the embryo is implanted in the scar after a previous Caesarean section. The most characteristic symptoms are vaginal bleeding and abdominal pain. However, CSP may also be asymptomatic. That is why all pregnant patients with a record of a prior Caesarean delivery should be examined by ultrasound at an early stage of pregnancy in order to identify the localisation of the gestational sac and check for a Caesarean scar.

Even though there are various approaches to the treatment of CSP (both surgical and non-surgical) and there are no strictly defined guidelines, early termination is strongly recommended due to the risk of massive bleeding and life-threatening complications.

Non-surgical methods are based on the administration of MTX, whereas surgical treatments consist of removing the GS from the scar $[6,7]$.

MTX is a chemotherapeutic agent applied in the treatment of ectopic pregnancy. When administered intra-arterially, directly to the uterine arteries, it is used in a more concentrated form compared to systemic administration. The function of the gelatine sponge is twofold: it binds a certain amount of MTX, promoting its prolonged release ( $24-48 \mathrm{~h}$ ), and it reduces the risk of bleeding after the abortion.

Lian et al. [8] reported 21 cases of CSP, of whom nine were treated with systemic MTX and the remaining 12 underwent additional uterine artery embolisation with Gelfoam sponge particles and local MTX application. Those authors concluded that the latter type of treatment might be superior in cases of deep implantation of the amniotic sac.

Ma et al. [9] compared the efficacy of two different embolic agents used in embolisation for CSP: gelatine sponge (GS) (22 patients), and polyvinyl alcohol (PVA) particles (13 patients). Both methods proved to have a relatively good first-scheme success rate $(92.3 \%$ for the PVA group and $86.4 \%$ for the GS group; no statistically significant difference was found between the two groups). The rate of adverse events defined as excessive bleeding was lower (but not statistically significantly so) for the PVA group - 1 (7.7\%) patient, compared to 8 (36.4\%) patients in the GS group. Conversely, the number of patients with a reduced menstrual blood volume was significantly lower in the GS group (8.3\%, compared to $50 \%$ in the PVA group).

We used gelatine sponge powder mixed with MTX to reduce the flow and, in this way, to prevent the migration of the chemotherapeutic agent to the systemic circulation and mitigate the risk of system- 
Table II. Overview of literature on treatment and outcomes of patients with CSP

\begin{tabular}{|c|c|c|c|c|c|}
\hline Study & Patients & Treatment & $\begin{array}{c}\text { UAC primary } \\
\text { procedure failure (\%) }\end{array}$ & $\begin{array}{l}\text { Hospitalisation } \\
\text { [days] }\end{array}$ & $\begin{array}{c}\text { Pregnancy rate } \\
(\%)\end{array}$ \\
\hline Ben Nagi [10] & 40 & $\begin{array}{c}\text { D\&C } n=28 \\
\text { MTX } n=9 \\
\text { Observation } n=3\end{array}$ & & $\begin{array}{l}\text { N/A } \\
\text { N/A } \\
\text { N/A }\end{array}$ & $\begin{array}{l}88 \\
\text { N/A } \\
\text { N/A }\end{array}$ \\
\hline Wang [11] & 71 & $\begin{array}{c}\text { MTX } \\
\text { MTX, D\&C }\end{array}$ & & $\begin{array}{l}\text { N/A } \\
\text { N/A }\end{array}$ & N/A \\
\hline Yang [12] & 66 & $\begin{array}{l}\text { D\&C } n=11 \\
M T X n=17 \\
\text { UAC } n=38\end{array}$ & 10.5 & $\begin{array}{c}22 \\
16.7 \\
12.5 \\
\end{array}$ & $\begin{array}{l}10.6 \\
\text { N/A } \\
\text { N/A }\end{array}$ \\
\hline Hong [13] & 152 & $\begin{array}{l}\text { HIFU } n=85 \\
\text { UAC } n=67\end{array}$ & 11.9 & $\begin{array}{l}7.7 \\
8.6\end{array}$ & N/A \\
\hline Junhong [7] & 87 & $\begin{array}{c}\operatorname{UAC} n=51 \\
\operatorname{LCSPDS} n=36\end{array}$ & 19.6 & $\begin{array}{l}12.6 \\
7.7\end{array}$ & N/A \\
\hline Tumenjargal [5] & 33 & UAC $n=33$ & 12.1 & 6.5 & 43.8 \\
\hline This study & 41 & UAC $n=41$ & 17 & 5.8 & 41.7 \\
\hline
\end{tabular}

scopic caesarean scar pregnancy debridement surgery, N/A - not available.

ic toxicity. In our opinion, the density of the gelatine sponge and MTX mixture was low enough to allow fast recanalisation and restoration of the blood flow to the temporarily occluded vessel.

Table II compares selected findings of this study with the results obtained by other authors [5, 7, 10-13]. Our experiences with UAC in the treatment of CSP over the last 6 years clearly demonstrate that it is a safe and efficient treatment method. Nevertheless, it has to be remembered that the success of embolisation might be compromised by the fact that blood may be supplied to the uterus by collateral arteries. The most common source of collateral blood supply to the uterus is via the ovarian arteries. In the current study, collateral blood supply from ovarian arteries was observed in $8.3 \%$ of the patients, which is in agreement with previous studies [14]. Collateral blood supply to the uterus from the superior vesical artery is an extremely rare finding. Treatment failure in one of our patients was attributed to residual flow to the gestational sac from the superior vesical artery, which was successfully embolised in the repeat procedure. There are no reports on collateral circulation to the uterus originating from the superior vesical artery.

In our study, 6 out of 36 women (16.7\%) reported menstrual cycle disturbances: four of them suffered from amenorrhoea and two experienced hypomenorrhoea. One possible explanation might be the presence of utero-ovarian anastomoses. Several authors have reported the presence of such anastomoses in patients who have undergone a Caesarean section [15-20]. Anastomoses could cause inadvertent embolisation of the ovaries with MTX and/or embolic agents, inducing premature ovarian failure. To prevent non-target embolisation, UAC is performed using 700-900 $\mu \mathrm{m}$ microspheres. Gelatine sponge powder is a non-calibrated material, but the size of the particles, after mixing with contrast, is optimal in the sense that it both ensures resorbability and prevents migration.

\section{Conclusions}

Our findings show that UAC is a safe and effective method that should be considered as an option in the treatment of CSP, especially for women who want to preserve their fertility. However, the presence of collateral blood supply should always be taken into account. Persistent foetal heart rate and/ or blood flow after the procedure should be an indication for repeat angiography.

\section{Conflict of interest}

The authors declare no conflict of interest.

\section{References}

1. Larsen JV, Solomon MH. Pregnancy in a uterine scar sacculusan unusual cause of postabortal haemorrhage. A case report. S Afr Med J 1978; 53: 142-3.

2. Jurkovic D, Hillaby K, Woelfer B, et al. First-trimester diagnosis and management of pregnancies implanted into the lower 
uterine Caesarean section scar. Ultrasound Obstet Gynecol 2003; 21: 220-7.

3. Diagnosis and Management of Ectopic Pregnancy: Green-top Guideline No. 21. BJOG. 2016; 13: e15-55.

4. Maheux-Lacroix S, Li F, Bujold E, et al. Cesarean scar pregnancies: a systematic review of treatment options. J Minim Invasive Gynecol 2017; 24: 915-25.

5. Tumenjargal A, Tokue H. Uterine artery embolization combined with dilation and curettage for the treatment of cesarean scar pregnancy: efficacy and future fertility. Cardiovasc Intervent Radiol 2018; 41: 1165-73.

6. Yufeng $\mathrm{H}$, Quanwei $\mathrm{G}$,Yingjie P, et al. Outcome of high-intensity focused ultrasound and uterine artery embolization in the treatment and management of cesarean scar pregnancy. Medicine 2017; 30: e7687.

7. Junhong G, Jiangtao Y, Qing Z, et al. Clinical efficacy and safety of uterine artery embolization (UAE) versus laparoscopic cesarean scar pregnancy debridement surgery (LCSPDS) in treatment of cesarean scar pregnancy. Med Sci Monit 2018; 24: 4659-66.

8. Lian F, Wang Y, Chen W, et al. Uterine artery embolization combined with local methotrexate and systemic methotrexate for treatment of cesarean scar pregnancy with different ultrasonographic pattern. Cardiovasc Intervent Radiol 2012; 35: 286-91.

9. Ma Y, Yang C, Shao X. Efficacy comparison of transcatheter arterial embolization with gelatin sponge and polyvinyl alcohol particles for the management of cesarean scar pregnancy and follow-up study. J Obstet Gynaecol Res 2017; 43: 682-8.

10. Ben Nagi S, Helmy D, Ofili-Yebovi J, et al. Reproductive outcomes of women with a previous history of Caesarean scar ectopic pregnancies. Hum Reprod 2007; 22: 2012-5.

11. Wang J, Kai-Hong X. Methotrexate therapy for cesarean section scar pregnancy with and without suction curettage. Fertil Steril 2009; 92: 1208-13.

12. Yang Y, Yu H, Li KM, et al. Uterine artery embolisation combined with local methotrexate for treatment of caesarean scar pregnancy. BJOG Int J Obstet Gynaecol 2010; 117: 990-6.

13. Hong Y, Quanwei G, Yingjie P, et al. Outcome of high-intensity focused ultrasound and uterine artery embolization in the treatment and management of cesarean scar pregnancy. A retrospective study. Medicine 2017; 30: e7687.

14. Pelage JP, Walker WJ, Le Dref O, et al. Ovarian artery: angiographic appearance, embolization and relevance to uterine fibroid embolization. Cardiovasc Intervent Radiol 2003; 26: 227-33.

15. Kobayashi T, Kusano S, Matsubayashi T, et al. Selective embolization of the vesical artery in the management of massive bladder hemorrhage. Radiology 1980; 136: 345-8.

16. Abbara S, Nikolic B, Pelage JP, et al. Frequency and extent of uterine perfusion via ovarian arteries observed during uterine artery embolization for leiomyomas. AJR Am J Roentgenol 2007; 188: 1558-63.

17. Lanciego C, Diaz-Plaza I, Ciampi JJ, et al. Utero-ovarian anastomoses and their influence on uterine fibroid embolization. J Vasc Interv Radiol 2012; 23: 595-601.

18. Marx M, Wack JP, Baker EL, et al. Ovarian protection by occlusion of uteroovarian collateral vessels before uterine fibroid embolization. J Vasc Interv Radiol 2003; 14: 1329-32.
19. Tulandi T, Sammour A, Valenti D, et al. Images in endoscopy: uterine artery embolization and utero-ovarian collateral. J Am Assoc Gynecol Laparosc 2001; 8: 474.

20. Andrews RT, Bromley PJ, Pfister ME. Successful embolization of collaterals from the ovarian artery during uterine artery embolization for fibroids: a case report. J Vasc Interv Radiol 2000; 11: 607-10.

Received: 25.06.2020, accepted: 16.09.2020. 